\title{
Predictive Value of Red Cell Volume Distribution Width-to- Platelet Ratio in Staging Liver Fibrosis in Chronic HCV-Infected Patients
}

\author{
Ali Saad Nada ${ }^{1}$, Nashwa Shebl ${ }^{1}$, Ahmed Ragab El-Gazzarah ${ }^{2}$, \\ Warda Othman ${ }^{1}$ \\ ${ }^{1}$ Department of Hepato-Gastroenterology, National Liver Institute, Menoufia \\ University, Egypt. \\ ${ }^{2}$ Department of Tropical Medicine department, Faculty of medicine, Menoufia \\ University. Egypt.
}

Corresponding Author Ahmed Ragab ElGazzarah

Mobile: 01009525523 01270736429

E mail: aragab0@gmail.com

Key words: $H C V, R D W, R P R$, APRI, FIB-4, liver cirrhosis, liver biopsy.
Background and study aim: The gold standard investigation to stage hepatic cirrhosis is liver biopsy. Being invasive with several major and minor procedurerelated complications, liver biopsy is not universally-applied in all the indicated population. In addition to observer-related variations and sampling errors, the need for alternatives to liver biopsy has emerged including several lab-based indices of those; red cell volume distribution width-to-platelet ratio (RPR) have been postulated in some studies. The aim of this article is to study the diagnostic performance of RPR in staging liver cirrhosis in $\mathrm{HCV}$-infected patients.

Patients and Methods: 236 patients who had underwent liver biopsy for IFN-based therapy were included in the present study according to pre-defined inclusion and exclusion criteria. They were classified into 4 groups according to the stage of

\section{INTRODUCTION}

HCV was discovered in 1989 and since then, it has been recognized as a major cause for chronic liver diseases worldwide accounting for more than $50 \%$ of infected cases [1].

The WHO reported that about 71 million people were $\mathrm{HCV}$-infected in 2015 , accounting for $1 \%$ of the total population. Its prevalence is not homogenously distributed worldwide, with a general prevalence ranging $0.5-6.5 \%$ worldwide. In south-east Asia and cirrhosis reported by the liver biopsy. Laboratory data, including $\mathrm{CBC}$ and biochemical studies, RPR, APRI score and FIB-4 were tabulated for statistical analysis.

Results: The AUROCs values for RPR were $0.795,0.811$ and 0.886 for F2, F3 and F4 stage of cirrhosis respectively which were consistently higher than those of APRI $(0.680,0.754$ and 0.746 for F2, F3 and F4 stages respectively) and FIB-4 $(0.653,0.765$ and 0.810 for F2, F3 and F4 stages respectively). RPR was significantly-correlated with APRI $(\mathrm{P}<0.002)$, and FIB-4 $(\mathrm{P}<0.001)$ for the prediction of F3 stage of cirrhosis, and F4 stage of cirrhosis $(\mathrm{P}<0.001 \& \mathrm{P}=0.03$ with APRI \& FIB-4 respectively).

Conclusion: RPR can be a promising, inexpensive non-invasive tool for the prediction of the stage of hepatic cirrhosis in patients with HCV. in eastern Mediterranean regions it reaches $2.3 \%$ [2].Egypt had the highest prevalence of $\mathrm{HCV}$ infection, and $92.5 \%$ of $\mathrm{HCV}$ infections belong to genotype 4 , $3.6 \%$ of infections belonging to genotype $1,3.9 \%$ of infections belonging to other genotypes [3].

The gold standard investigation to stage hepatic cirrhosis is liver biopsy. Being invasive with several major and minor procedure-related complications, liver biopsy is not universally- 
applicable in all the indicated population. In addition, a significant fraction of observerrelated variations and sampling errors exists [4].

Furthermore, repeated biopsy is not applicable to monitor the fibrotic regression in the era of DAAs. As a result, several non-invasive alternatives have been studied and proved reasonable usefulness for estimating the stage of hepatocirrhosis of different etiologies. These methods included transient elastography (TE), APRI and FIB-4 scores. Being non-invasive, highly accurate, TE has proved to be a trusted alternative to liver biopsy. However, due to its limited availability (mostly available in tertiary healthcare centers), many of biopsy-indicated patients won't be able to make use of its benefits [5].

Red cell distribution width (RDW) is reported routinely by clinical labs as a part of the regular complete blood count. It is used to diagnose the etiology of anemia. It is calculated as the quotient of the standard deviation of the RBC size to the mean corpuscular volume, and it reflects the variation of heterogeneity in the volume of RBCs. Increased RDW indicates dysfunctional erythropoiesis, shortened RBC lifespan, or premature release of reticulocytes. Traditionally, RDW has been used in diagnosing iron deficiency anemia (particularly if serum ferritin is inconclusive), folate or vitamin B12 deficiency anemia. Recently, a positive correlation had been proposed between RDW and both of morbidity and mortality in several disease states, principally in severely-ill patients. These conditions include renal disease, multiple cardiovascular diseases and interventions (such as coronary interventions), multiple sclerosis, and inflammatory bowel disease. This can be rationalized by the elevated levels of circulating inflammatory mediators $[\mathbf{6 , 7 , 8 ]}$.

Recent studies have shown that RDW correlates significantly with the fibrosis stage in patients with NASH and chronic HBV infection [9,10].

Multiple mechanisms are involved in the pathogenesis of HCV-related thrombocytopenia. The prevalence of thrombocytopenia in chronic $\mathrm{HCV}$ infection is estimated to be about $24 \%$. In addition to eliciting an autoimmune reaction with production of anti-platelet antibodies, HCV has a direct bone marrow suppressing effect that eventually results in thrombocytopenia [11].

\section{PATIENTS AND METHODS}

This retrospective study included 236 patients who had underwent liver biopsy for IFN-based therapy at National Liver Institute- Menoufia University during January 2014 to August 2014. After taking permission, we checked the files containing the clinical and lab data of these patients. Inclusion criteria: Patients aged 18-60 years old, no chronic medical disorders of cardiac, renal, collagen disease or malignancy with $\mathrm{Hb} \%>12 \mathrm{~g} / \mathrm{dL}$, average TLC, Platelet count $>100.000 \mathrm{~mm}^{3}$. Exclusion criteria: clinical data of any of the pre-defined medical disorders, $\mathrm{Hb} \%$ $<12$ g/dL, abnormal TLC, Platelet count $<100.000 \mathrm{~mm}^{3}$, biopsy results of hepatic pathology other than HCV-related hepatocirrhosis. Based on these inclusion and exclusion criteria; 236 patients were selected and were classified into 4 groups according to the stage of cirrhosis reported by the liver biopsy examination according to Metavir score:

Group I ( $n=41)$ : Patients with cirrhosis stages F0-F1

Group II ( $n=43)$ : Patients with cirrhosis stage F2

Group III ( $n=48)$ : Patients with cirrhosis stage F3

Group IV (n=104): Patients with cirrhosis stages F4

All laboratory results, $(\mathrm{CBC}$, liver profiles and kidney functions) were tabulated for statistical analysis. In addition, the following ratios were calculated:

1) RPR was calculated from the following formula using RDW and platelet counts:

$\mathrm{RPR}=\mathrm{RDW}(\%) /$ Platelet count $\left(10^{9} / \mathrm{L}\right)[\mathbf{1 2}]$.

2) The FIB-4 index was calculated from the following formula:

FIB-4 = (Age $\mathrm{x}$ AST $) /($ Platelet count $\mathrm{x}$ VALT) [13].

3) The APRI was calculated from the following formula:

([AST [IU/L]/upper limit of normal] $\mathrm{X}$ $100 /$ platelet count $\left.\left[10^{9} / \mathrm{L}\right]\right)[\mathbf{1 4}]$.

\section{RESULTS}

- $81 \%$ of the included patients were males (191/236), $19 \%$ of them were females (45/236), their ages ranged $22-58$ years. There was a statistically-insignificant difference 
between the studied groups regarding age and sex distribution ( $\mathrm{p}>0.05)$ (Table 1).

- The mean $\pm \mathrm{SD}$ for RDW, Platelet count, RPR, APRI and FIB-4 of the studied patients are tabulated in (Table 2). The results indicated that each mean value for RDW, Platelet count, RPR, APRI and FIB-4 were running progressively in correspondence with the stage of cirrhosis with a high statisticallysignificant difference $(\mathrm{p}<0.001)$.

- Statistical analysis of the results of $\mathrm{HB} \%$, platelet counts, transaminases, serum albumin, bilirubin, INR, and AFP levels revealed a high statistically-significant variation $(p<0.001)$ that matches the progression of the stage of fibrosis. There was a statistically-insignificant difference regarding WBCs count and serum creatinine $(\mathrm{p}>0.05)$ (table 3$)$.

- Using a cut-off value of 0.049 ; RPR can diagnose F2 stage of cirrhosis with a sensitivity of $84.23 \%$, specificity of $61.74 \%$, PPV of $69.2 \%$, NPV of $78.1 \%$. At a cut-off value of 0.074 , RPR can diagnose F3 stage of cirrhosis with a sensitivity of $72.92 \%$, specificity of $81.4 \%$, PPV of $80.9 \%$, NPV of $73.5 \%$. At a cut-off value of 0.099 , RPR can diagnose F4 stage of cirrhosis with a sensitivity of $88.46 \%$, specificity of $75 \%$, PPV of $85 \%$, NPV of $75.4 \%$.

- The results for diagnostic indices and cut-off values for RDW, platelet count, RPR, FIB4 and APRI are presented in (Table 4). RPR had sensitivity and specificity profiles that were more reasonable than APRI and FIB-4 at different stages of cirrhosis.

- AUROCs for the studied indices are shown in table 5. The AUROCs values for RPR were $0.795,0.811$ and 0.886 for F2, F3 and F4 stage of cirrhosis respectively. They were consistently higher than those of APRI (0.680, 0.754 and 0.746 for F2, F3 and F4 stages respectively) and FIB-4 (0.653, 0.765 and 0.810 for $\mathrm{F} 2, \mathrm{~F} 3$ and F4 stages respectively). RPR was significantlycomparable to APRI $(\mathrm{P}<0.002)$, and FIB-4 $(\mathrm{P}<0.001)$ for the prediction of $\mathrm{F} 3$ stage of cirrhosis, and $\mathrm{F} 4$ stage of cirrhosis $(\mathrm{P}<0.001$ $\& \mathrm{P}=0.03$ with APRI \& FIB-4 respectively).

Table (1): Comparison between demographic data in the four groups.

\begin{tabular}{|c|c|c|c|c|c|c|c|c|c|c|c|}
\hline \multirow[b]{3}{*}{ Age (years) } & \multirow{3}{*}{\begin{tabular}{|l|}
$\mathrm{X} \pm$ SD \\
Range \\
\end{tabular}} & \multicolumn{2}{|c|}{$\begin{array}{c}\text { Group I } \\
(n=41)\end{array}$} & \multicolumn{2}{|c|}{$\underset{(n=43)}{\text { Group II }}$} & \multicolumn{2}{|c|}{$\begin{array}{c}\text { Group III } \\
(n=48)\end{array}$} & \multicolumn{2}{|c|}{$\begin{array}{c}\text { Group IV } \\
(n=104)\end{array}$} & ANOVA & P- Value \\
\hline & & \multirow{2}{*}{\multicolumn{2}{|c|}{$\frac{40.98 \pm 12.370}{22-55}$}} & \multirow{2}{*}{\multicolumn{2}{|c|}{$\frac{40.23 \pm 7.622}{32-58}$}} & \multirow{2}{*}{\multicolumn{2}{|c|}{$43.02 \pm 8.017$}} & \multicolumn{2}{|c|}{$41.46 \pm 7.270$} & \multirow{2}{*}{0.869} & \multirow{2}{*}{0.458} \\
\hline & & & & & & & & & & & \\
\hline \multirow{4}{*}{ Sex } & & $\mathbf{N}$ & $\%$ & $\mathbf{N}$ & $\%$ & $\mathbf{N}$ & $\%$ & $\mathbf{N}$ & $\%$ & \multirow[t]{2}{*}{$X^{2}$} & \multirow[t]{2}{*}{ P- Value } \\
\hline & Male & 35 & 85.37 & 36 & 83.72 & 35 & 72.92 & 85 & 81.73 & & \\
\hline & Female & 6 & 14.63 & 7 & 16.27 & 13 & 27.08 & 19 & 18.27 & \multirow[t]{2}{*}{2.412} & \multirow[t]{2}{*}{0.491} \\
\hline & Total & 41 & 100 & 43 & 100 & 48 & 100 & 104 & 100 & & \\
\hline
\end{tabular}

Table (2): Comparison between routine laboratory parameters in different fibrosis stages

\begin{tabular}{|c|c|c|c|c|c|c|}
\hline & $\begin{array}{c}\text { Group I } \\
(\mathbf{n}=\mathbf{4 1})\end{array}$ & $\begin{array}{c}\text { Group II } \\
(\mathbf{n}=\mathbf{4 3})\end{array}$ & $\begin{array}{c}\text { Group III } \\
(\mathbf{n}=\mathbf{4 8})\end{array}$ & $\begin{array}{c}\text { Group IV } \\
(\mathbf{n = 1 0 4})\end{array}$ & F & P-value \\
\hline Hb & $15.934 \pm 0.852$ & $14.786 \pm 1.648$ & $14.892 \pm 1.446$ & $13.900 \pm 1.618$ & 19.595 & $<0.001$ \\
\hline RDW & $13.989 \pm 0.793$ & $14.262 \pm 1.446$ & $14.967 \pm 1.024$ & $15.854 \pm 1.524$ & 2.661 & 0.045 \\
\hline TLC $\left.(\mathbf{X 1 0})^{3}\right)$ & $6.839 \pm 1.876$ & $6.746 \pm 1.952$ & $7.504 \pm 1.887$ & $5.971 \pm 2.211$ & 6.643 & 0.563 \\
\hline Platelets $\left.(\mathbf{X 1 0})^{3}\right)$ & $256.682 \pm 65.800$ & $218.441 \pm 46.129$ & $167.625 \pm 46.988$ & $112.294 \pm 30.735$ & 144.773 & $<0.001$ \\
\hline Creatinine & $0.844 \pm 0.207$ & $0.837 \pm 0.179$ & $0.830 \pm 0.174$ & $0.839 \pm 0.240$ & 0.038 & 0.990 \\
\hline Albumin & $4.417 \pm 0.161$ & $4.328 \pm 0.291$ & $4.188 \pm 0.270$ & $3.821 \pm 0.494$ & 34.487 & $<0.001$ \\
\hline ALT & $40.049 \pm 12.072$ & $45.419 \pm 13.043$ & $81.063 \pm 21.575$ & $81.452 \pm 17.545$ & 14.023 & $<0.001$ \\
\hline AST & $32.951 \pm 11.715$ & $37.930 \pm 11.432$ & $93.875 \pm 23.783$ & $105.539 \pm 29.315$ & 24.847 & $<0.001$ \\
\hline Bilirubin & $0.537 \pm 0.137$ & $0.644 \pm 0.221$ & $0.783 \pm 0.301$ & $1.044 \pm 0.506$ & 22.873 & $<0.001$ \\
\hline AFP & $3.181 \pm 0.997$ & $3.443 \pm 1.417$ & $9.425 \pm 12.507$ & $20.264 \pm 9.895$ & 10.587 & $<0.001$ \\
\hline INR & $1.081 \pm 0.040$ & $1.037 \pm 0.079$ & $1.071 \pm 0.107$ & $1.146 \pm 0.155$ & 10.415 & $<0.001$ \\
\hline
\end{tabular}

Nada et al., Afro-Egypt J Infect Endem Dis 2020 ;10(4) :356-363

https://aeji.journals.ekb.eg/

Http://mis.zu.edu.eg/ajied/home.aspx 
Table (3): Values for each non-invasive method at each fibrosis stage.

\begin{tabular}{|c|c|c|c|c|c|c|}
\hline & $\begin{array}{c}\text { Group I } \\
(\mathbf{n}=\mathbf{4 1})\end{array}$ & $\begin{array}{c}\text { Group II } \\
(\mathbf{n}=\mathbf{4 3})\end{array}$ & $\begin{array}{c}\text { Group III } \\
(\mathbf{n = 4 8})\end{array}$ & $\begin{array}{c}\text { Group III } \\
(\mathbf{n}=\mathbf{1 0 4})\end{array}$ & \multirow{2}{*}{$\mathbf{F}$} & \multirow{2}{*}{ P-value } \\
\cline { 2 - 5 } & $\mathbf{X} \pm \mathbf{S D}$ & $\mathbf{X} \pm$ SD & $\mathbf{X} \pm$ SD & $\mathbf{X} \pm \mathbf{S D}$ & & \\
\hline RPR & $0.059 \pm 0.019$ & $0.063 \pm 0.014$ & $0.088 \pm 0.025$ & $0.149 \pm 0.057$ & 74.583 & $<0.001$ \\
\hline APRI & $0.276 \pm 0.082$ & $0.400 \pm 0.188$ & $1.320 \pm 0.705$ & $2.272 \pm 1.430$ & 57.194 & $<0.001$ \\
\hline Fib4 & $0.854 \pm 0.260$ & $1.062 \pm 0.378$ & $2.822 \pm 1.109$ & $4.713 \pm 1.968$ & 108.558 & $<0.001$ \\
\hline
\end{tabular}

Table (4): Diagnostic performance of RPR, APRI and FIB-4 and their optimal cut-off values

\begin{tabular}{|c|c|c|c|c|c|c|c|c|c|}
\hline & Stage & AUROC $(95 \%$ CI $)$ & Cut-off & $\begin{array}{c}\text { Sensitivity } \\
\% \\
\end{array}$ & $\begin{array}{c}\text { Specificity } \\
\% \\
\end{array}$ & $\begin{array}{c}\text { PPV } \\
\%\end{array}$ & $\begin{array}{c}\text { NPV } \\
\%\end{array}$ & $+\mathrm{LR}$ & -LR \\
\hline \multirow[t]{3}{*}{ RDW\% } & F2 & $0.680(0.569-0.778)$ & 13.5 & 72.09 & 80.49 & 96.9 & 25.3 & 3.69 & 0.35 \\
\hline & F3 & $0.733(0.626-0.832)$ & 13.9 & 66.67 & 67.44 & 69.5 & 64.5 & 2.05 & 0.49 \\
\hline & F4 & $0.761(0.678-0.841)$ & 14.5 & 55.77 & 0.83 & 80.5 & 42.5 & 1.61 & 0.62 \\
\hline \multirow{3}{*}{$\begin{array}{l}\text { Platelet } \\
\text { X } 10^{9} / \mathrm{L}\end{array}$} & F2 & $0.644(0.532-0.745)$ & 216 & 83.72 & 60.98 & 66.4 & 80.2 & 2.15 & 0.27 \\
\hline & F3 & $0.800(0.703-0.876)$ & 154 & 75.00 & 79.07 & 76.8 & 77.4 & 3.58 & 0.32 \\
\hline & $\mathrm{F} 4$ & $0.803(0.731-0.863)$ & 108 & 78.85 & 70.83 & 85.2 & 61.2 & 2.7 & 0.3 \\
\hline \multirow[t]{3}{*}{ RPR } & $\mathrm{F} 2$ & $0.795(0.682-0.901)$ & 0.049 & 84.23 & 61.74 & 69.2 & 78.1 & 2.15 & 0.27 \\
\hline & F3 & $0.811(0.716-0.886)$ & 0.074 & 72.92 & 81.4 & 80.9 & 73.5 & 1.96 & 0.5 \\
\hline & F4 & $0.855(0.789-0.907)$ & 0.099 & 88.46 & 75 & 85 & 75.4 & 3.92 & 0.33 \\
\hline \multirow[t]{3}{*}{ APRI } & F2 & $0.680(0.569-0.777)$ & 0.366 & 41.86 & 100 & 88.3 & 58.1 & 0.0 & 0.58 \\
\hline & F3 & $0.754(0.688-0.787)$ & 0.822 & 83.33 & 100 & 100 & 84.7 & 0.0 & 0.17 \\
\hline & F4 & $0.822(0.699-0.813)$ & 1.580 & 61.54 & 83.33 & 88.9 & 50 & 3.69 & 0.46 \\
\hline \multirow[t]{3}{*}{ FIB-4 } & F2 & $0.653(0.541-0.753)$ & 1.24 & 78.21 & 100 & 100 & 59.2 & 0.0 & 0.63 \\
\hline & F3 & $0.765(0.704-0.792)$ & 1.6 & 87.50 & 93.02 & 93.3 & 87.0 & 12.54 & 0.13 \\
\hline & $\mathrm{F} 4$ & $0.762(0.686-0.827)$ & 2.92 & 85.58 & 62.5 & 82.9 & 67.1 & 2.28 & 0.23 \\
\hline
\end{tabular}

Table (5): Correlations of AUROCs between RPR and other non-invasive predictors.

\begin{tabular}{|c|c|c|c|}
\hline Fibrosis Stage & Models & AUROC (95\% CI) & P value* \\
\hline \multirow{5}{*}{ F2 } & RPR & $0.795(0.682-0.901)$ & \\
\hline & RDW & $0.680(0.569-0.778)$ & 0.297 \\
\hline & Platelet & $0.644(0.5320 .745)$ & 0.636 \\
\hline & APRI & $0.680(0.569-0.777)$ & 0.341 \\
\hline & Fib 4 & $0.653(0.541-0.753)$ & 0.494 \\
\hline \multirow{5}{*}{ F3 } & RPR & $0.811(0.716-0.886)$ & \\
\hline & RDW & $0.733(0.626-0.832)$ & 0.5817 \\
\hline & Platelet & $0.800(0.703-0.876)$ & 0.028 \\
\hline & APRI & $0.754(0.688-0.787)$ & 0.002 \\
\hline & Fib 4 & $0.765(0.704-0.792)$ & $<0.001$ \\
\hline \multirow{5}{*}{ F4 } & RPR & $0.855(0.789-0.907)$ & \\
\hline & RDW & $0.761(0.678-0.841)$ & $<0.032$ \\
\hline & Platelet & $0.803(0.731-0.863)$ & $<0.001$ \\
\hline & APRI & $0.822(0.699-0.813)$ & $<0.001$ \\
\hline & Fib 4 & $0.762(0.686-0.827)$ & 0.03 \\
\hline
\end{tabular}




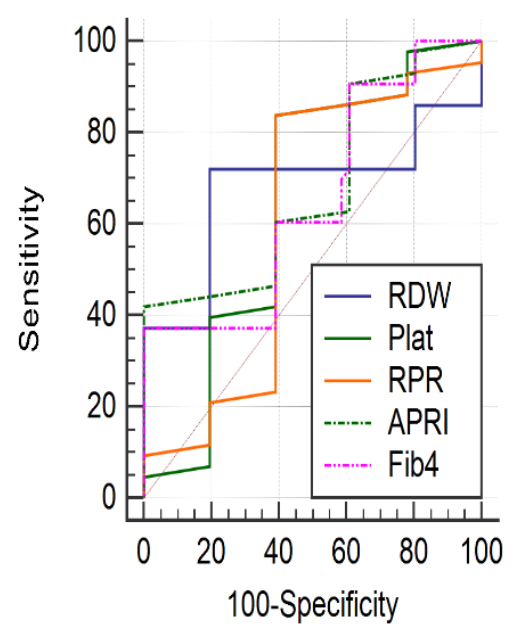

Figure 1: ROC curve for different predictors for $\mathrm{F} 2$ stage of cirrhosis.

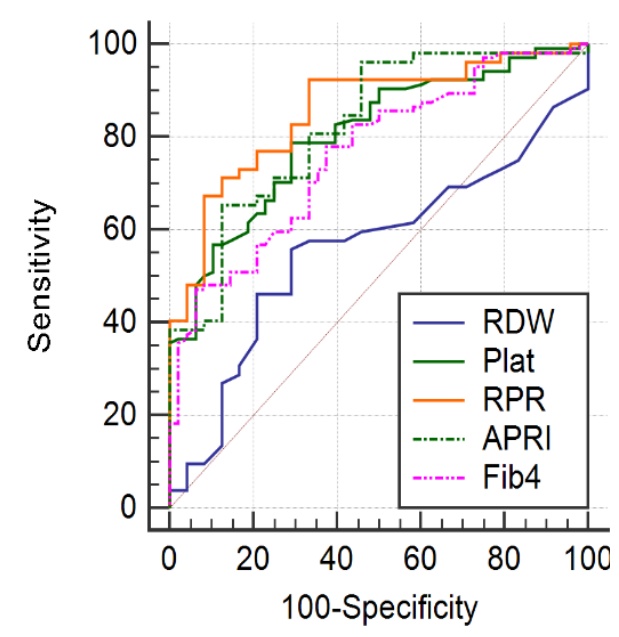

Figure 2: ROC curve for different predictors for F3 stage of cirrhosis.

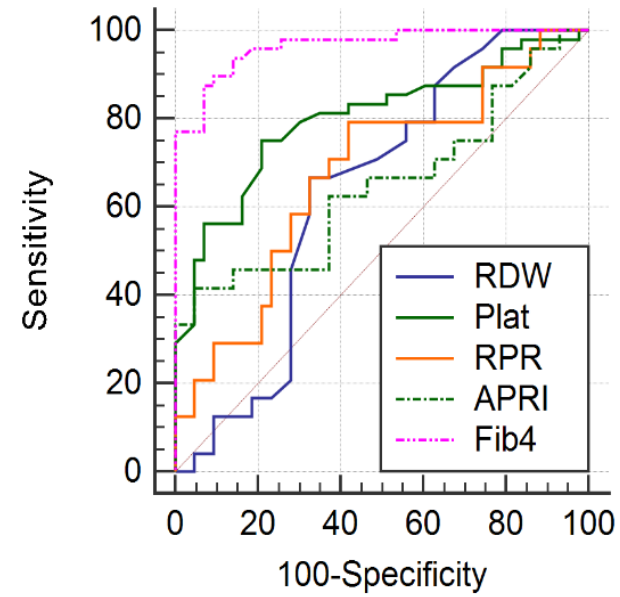

Figure 3: ROC curve for different predictors for $\mathrm{F} 4$ stage of cirrhosis.

\section{DISCUSSION}

HCV infection is almost always progressive either to hepatitis, cirrhosis. Liver biopsy is the definite method for staging hepatic cirrhosis. However, it is invasive and has several limiting contraindications (e.g. bleeding tendency, ascites, hemodynamically-unstable patients) [15].

The clinical implications of different components of CBC have been extensively studied and proved reasonable significance in prediction of disease severity or mortality risk. RDW has been reported to be concomitantly-elevated with increased mortality or poor outcomes of several diseases [16,17], and platelet count is an undebatable, dependable and simple predictor of hepatic fibrosis. It has been included in most of the predictive models for estimating hepatic fibrosis and cirrhosis [11]. Thus, the impregnation of these 2 parameters in a single equation is expected to yield a new index with higher diagnostic indices than any of the 2 parameters solely. Moreover, unlike APRI or FIB-4 scores, RPR is not influenced by the variation in transaminases levels which may fluctuate with disease activity or when other offending factors exist e.g. drug-induced liver injury.

In 2013, Chen et al. released a novel, simple and low-cost index that yielded a promising role in predicting the stage of cirrhosis in patients with
CHB. This index includes only two variables that are routinely reported in the $\mathrm{CBC}$, which are RDW and platelet count [12].

Before starting our study, we searched the published data about RPR and we found many studies about its role in staging hepatic cirrhosis in patients with HBV-related liver diseases, NAFLD and PBC. Because of the too many numbers of $\mathrm{HCV}$ cases in Egypt, we decided to conduct a similar study on HCV-infected patients to validate RPR usefulness in this category of liver-diseased patients. It was proposed that if proved promising; RPR will be extensively helpful in clinical practice for predicting the degree of hepatic cirrhosis in patients with HCVrelated cirrhosis specially when TE is not available.

There was a high statistically-significant difference between the studied groups regarding RDW\%, platelet count and RPR (table 3). This indicates that these indices run parallel with the progression of liver injury. In agreement with these results, Huang et al. reported that RDW could be a dependable indicator for predicting disease severity and they defined a cut-off of $16.07 \pm 2.41 \%, 13.29 \pm 1.09 \%$ and $12.75 \pm 0.70 \%$ for patients with HBV- related liver cirrhosis, non-cirrhotic CHB patients and healthy controls respectively [18].

Moreover; Lou et al. reported that RDW increases significantly in patients with chronic 
active HBV infection than in healthy controls. In addition, they reported that RDW in this population could predict a 3-month mortality risk [17].

In agreement with our results, Jin et al. reported that RDW and RPR rates are significantly-higher in patients with HCV-related cirrhosis than in those with non-active chronic HCV infection and healthy controls. In addition, they concluded that the RDW rates were significantly-correlated with the severity of liver disease estimated by MELD and CTP scores [19].

Though having higher AUROCs than FIB-4 and APRI score, RPR was insignificantly-comparable to FIB-4 $(\mathrm{P}=0.494)$ and APRI $(\mathrm{P}=0.341)$, for the prediction of early cirrhosis $(<\mathrm{F} 2$ stage of cirrhosis) but RPR was significantly-correlated to APRI $(\mathrm{P}<0.002)$, and FIB-4 $(\mathrm{P}<0.001)$ for the prediction of $\mathrm{F} 3$ stage of cirrhosis, and F4 stage of cirrhosis $(\mathrm{P}<0.001 \& \mathrm{P}=0.03$ with APRI \& FIB-4 respectively). This can be rationalized by the inclusion of transaminases in both scores and its absence in RPR. Being released from other tissues (e.g. RBCs, myocardium), AST may give over- or less-predicting results about hepatic injury.

In agreement with these results, Lee et al. reported a good diagnostic performance of RPR (AUROC $=0.801)$ in predicting significant fibrosis $(\geq F 2)$ and cirrhosis (F4) in patients with $\mathrm{CHB}$ that was comparable to FIB-4 (AUROC $=0.811$ ) and superior to APRI (AUROC $=0.680$ ) for diagnosing $\mathrm{F} 4$ stage of cirrhosis [20].

Also, Wang et al. concluded that RPR yielded a higher AUROC (0.711) than APRI $(0.648 ; P=$ $0.035)$ and FIB-4 $(0.682 ; P=0.009)$ in prediction of F4 stage of cirrhosis in patients with primary biliary cirrhosis [21].

Karagöz et al. reported an AUROC of 0.705 for RPR for predicting significant fibrosis $(>F 3)$ in chronic HCV-infected patients, which was superior to the APRI score of the studied groups [22].

There was a statistically-insignificant difference regarding TLC of the studied groups in this study. In contrast, Alkhouri et al. concluded that TLC was significantly-correlated with disease severity in patients with NASH. This could be due to different etiology of liver disease between both studies [23].

\section{CONCLUSION}

RPR is a cost-effective, dependable, noninvasive tool for the estimation of liver fibrosis in $\mathrm{HCV}$-infected patients. RPR proved to be comparable to FIB-4 and superior to APRI score in our study. RPR may be used as an alternative for liver biopsy in patients with $\mathrm{HCV}$, especially when TE is not available.

\section{List of Abbreviations:}

Hepatitis C Virus (HCV), Hepatitis B Virus (HBV), Direct Acting Antivirals (DAAs), Interferon (IFN), Hepatocellular carcinoma (HCC), Fibrosis score based on 4 factors (FIB4), Red blood cells (RBCs), RBC distribution width (RDW), RBCs distribution width/ Platelet Ratio (RPR), Aspartate aminotransferase (AST)to-platelet ratio score (APRI), Transient Elastography (TE), World Health Organization (WHO), Chronic Hepatitis B (CHB), NonAlcoholic Steatohepatitis (NASH), Hemoglobin $(\mathrm{Hb})$, Total leucocytic Count (TLC), Complete Blood Count (CBC), Model for End-Stage Liver Disease score (MELD score), Child-TurcottPugh score (CTP score).

\section{Highlights}

- Liver biopsy is the gold standard for assessing hepatic histology including staging hepatic cirrhosis. However, its invasive nature, risk of minor and major complications, intra- and inter-observer variability and sampling error makes it inconvenient to all cases.

- The need for non-invasive models have resulted in development of several models that compete each other in the simplicity, availability and cost issues.

- Of the most emerging models, RPR has the benefit of not depending on transaminases, low cost, and having promising diagnostic profiles when compared to traditional models like APRI score and FIB-4.

Funding: No funding resources

Conflict of Interest: the authors declare that there was no conflict of interest. 


\section{Ethical consideration:}

This study was carried out in conformity with the Declaration of Helsinki. The study protocol was notarized by the Ethics Committee of the Faculty of Medicine, and National Liver Institute, Menoufia University.

\section{REFERENCES}

1. Shepard CW, Finelli L and Alter MJ. Global epidemiology of hepatitis C virus infection. Lancet Infect Dis 2005; 5: 558-567.

2. Petruzziello A, Marigliano S, Loquercio G, Cozzolino A, Cacciapuoti C. Global epidemiology of hepatitis $\mathrm{C}$ virus infection: An update of the distribution and circulation of hepatitis C virus genotypes. World $J$ Gastroenterol 2016; 22(34): 7824-7840.

3. Kouyoumjian SP, Chemaitelly H, Abu-Raddad LJ. Characterizing hepatitis C virus epidemiology in Egypt: systematic reviews, meta-analyses, and meta-regressions. Sci Rep 2018; 8:1661-1670.

4. Regev A, Berho M, Jeffers LJ, Milikowski C, Molina EG, Schiff ER et al. Sampling error and intra-observer variation in liver biopsy in patients with chronic $\mathrm{HCV}$ infection. Am J Gastroenterol 2002; 97: 2614-2622.

5. Christiansen KM, Mossner BK, Hansen JF, Jarnbjer EF, Pedersen C, Christensen PB. Liver stiffness measurement among patients with chronic hepatitis B and C: results from a 5-year prospective study. PLoS ONE 2014; 9: e111912.

6. Yoon HE, Kim SJ, Hwang HS, Chung S, Yang $\mathrm{CW}$, Shin SJ. Progressive rise in red blood cell distribution width predicts mortality and cardiovascular events in end-stage renal disease patients. PLoS ONE 2015; 10:e0126272.

7. Peng YF, Cao WY, Zhang Q. Assessment of the Relationship Between Red Cell Distribution Width and Multiple Sclerosis. Medicine 2015; 94:e1182.

8. Yeşil A, Senates E, Bayoglu IV. Red cell distribution width: a novel marker of activity in inflammatory bowel disease. Gut Liver 2011; 5:460-467.

9. Cengiz M, Candır BA, Yılmaz G. Is increased red cell distribution width an indicating marker of non-alcoholic steatohepatitis and fibrotic stage. World J Gastroenterol 2013; 19:74127418 .
10. Xu WS, Qiu XM, Ou QS. Red blood cell distribution width levels correlate with liver fibrosis and inflammation a noninvasive serum marker panel to predict the severity of fibrosis and inflammation in patients with hepatitis $\mathrm{B}$. Medicine 2015; 94:e612.

11. Osada M, Kaneko M, Sakamoto M, Endoh M, Takigawa K, Yatomi Y. Causes of thrombocytopenia in chronic hepatitis $\mathrm{C}$ viral infection. Clinical and Applied Thrombosis/Hemostasis 2012;18(3):272-280. https: //doi.org/10.1177/ 1076029611429124. [PubMed] [Google Scholar].

12. Chen B, Ye B, Zhang J, Ying L, Chen Y. RDW to platelet ratio: a novel non-invasive index for predicting hepatic fibrosis and cirrhosis in chronic hepatitis B. PLoS ONE 2013; 8: e68780.

13. Sterling RK, Lissen E, Clumeck N. Development of a simple noninvasive index to predict significant fibrosis in patients with HIV/HCV coinfection. Hepatology 2006; 43:1317-1325.

14. Wai CT, Greenson JK, Fontana RJ. A simple non-invasive index can predict both significant fibrosis and cirrhosis in patients with chronic hepatitis C. Hepatology 2003; 38: 518-526.

15. Qitian He, Quan He, Xue Qin, Shan Li, Taijie Li, Zhifu Wei et al. "The Relationship between Inflammatory Marker Levels and Hepatitis C Virus Severity." Gastroenterology Research and Practice vol. (2016): 2978479. doi:10.1155/2016/2978479.

16. Rickard J, Kumbhani DJ, Gorodeski EZ, Martin DO, Grimm RA, Wilkoff BL et al. Elevated red cell distribution width is associated with impaired reverse ventricular remodeling and increased mortality in patients undergoing cardiac resynchronization therapy. Congest Heart Fail 2012; 18: 79-84.

17. Lou Y, Wang M, Mao W. Clinical usefulness of measuring red blood cell distribution width in patients with hepatitis B. PLoS ONE 2012; 7: e37644.

18. Huang R, Yang C, Wu K. Red cell distribution width as a potential index to assess the severity of hepatitis B virus related liver diseases, Hepatology Research 2014; 44: E464-E470.

19. Jin L, Li X, Ye J. Value of red blood cell distribution width in assessing the severity of hepatitis $\mathrm{C}$ virus-related liver diseases, Zhonghua Gan Zang Bing Za Zhi 2016; 24:130132. 
20. Lee HW, Kang W, Kim BK, Kimm SU. Red cell volume distribution width-to-platelet ratio in assessment of liver fibrosis in patients with chronic hepatitis B. Liver Int 2016; 36: 24-30.

21. Wang $\mathrm{H}, \mathrm{Xu} \mathrm{H}$, Wang $\mathrm{X}$. Red Blood Cell Distribution Width to Platelet Ratio is Related to Histologic Severity of Primary Biliary Cirrhosis; Medicine 2016; 95(11): e3114.
22. Karagöz E, Tanoğlu A, Yazgan Y. Mean Platelet Volume and Red Cell Distribution Width to Platelet Ratio for Predicting the Severity of Hepatic Fibrosis in Patients with Chronic Hepatitis C. Eur J Gastroenterol Hepatol 2016 Jul;28(7):744-752.

23. Alkhouri N, Morris-Stiff G, Campbell C, Lopez R, Tamimi TA. Neutrophil to lymphocyte ratio: a new marker for predicting steatohepatitis and fibrosis in patients with nonalcoholic fatty liver disease. Liver international: official journal of the International Association for the Study of the Liver 2012; 32: 297-302. 